\title{
Needs Assessment of Patients with Obstructive Sleep Apnea at Assiut University Hospital
}

\author{
Ibrahem , N ., M ; Sayed , S ., S ; Hegazy , S ., M ; \& Mekkawy , M ., M. \\ Head Nurse of chest Department, Assiut University. \\ Professor of Chest Department, of Faculty of Medicine, Assiut University, Egypt. \\ Assistant Professor of Medical Surgical Nursing, Faculty of Nursing, Ain shams University, Egypt. \\ Assistant Professor of Medical-Surgical Nursing, Faculty of Nursing, Assiut University, Egypt.
}

\begin{abstract}
:
Objective: are in need for different types of support the aim of this study to assess the physical, social, psychological, spiritual and educational needs of patients with obstructive sleep apnea and its associated ith morbidities. Patient and Methods: A descriptive exploratory study design was conducted at the Sleep center in Chest Department at Assiut University Hospital. Sample: A purposive sample of 100 adult patients from both sexes with OSA. Tools: a Patients' interviewing questionnaire sheet, Epworth Sleepiness Scales, Respiratory disturbed index (RDI) after full Polysomnographic study, patients' medical record, and Hamilton Rating Scale. Results: The study findings revealed that $30 \%$ of the studied patients were illiterate, $44 \%$ of them basic education and $26 \%$ of them were university and postgraduates. Moreover, $80 \%$ of them were overweight and obese the BMI $>25,11 \%$ of them were smoker, added to them $68 \%$ of them had waist circumference $>102$ in male and $>88$ in female. And $29 \%$ had neck size $>45 \mathrm{~cm}$ in male and $>42 \mathrm{~cm}$ in female. Nearly, $96 \%$ of them had respiratory, $95 \%$ nocturia and $79 \%$ digestive systems problems. Furthermore, $87 \%$ of the studied patients had tired and fatigued, $83 \%$ had day time sleepiness, $82 \%$ had obstruction breathing during sleep, $100 \%$ moderate and severe OSA and not present any mild case of OSA. Conclusion: There was no statistically significant relation between patients' needs and their characteristics, levels of sleepiness and depression. Statistical significant relation between physical, social, psychological and educational needs, level of OSA and educational needs with educational level. Furthermore, there was no statistically significant relation between patients' needs and age group, gender, and BMI.
\end{abstract}

Key words: OSA, Patients needs, Polysomnography, Epworth Sleepiness Scale, Respiratory Disturbed Index \& HamiltonRatingScale.

\section{Introduction}

leep apnea is a condition in which breathing stops for more than 10 seconds during sleep and cause daytime sleepiness. It is a common disorder in which patients have one or more pauses in breathing or shallow breaths while they sleep. Breathing pauses can last from a few seconds to minutes. They often occur 5 to 30 times or more an hour and 3 or more nights each week (Cifci, 2011).

There are three forms of sleep apnea: obstructive (commonest type), central and mixed sleep apnea. In obstructive sleep apnea (OSA), breathing stops because pharyngeal muscles in the throat close off the airway. It is much more common than other type, can affect people of any age and of either sex, but is most common in middle-aged. It affects nearly one in four men and one in ten women. About, 18 million Americans, are thought to have sleep apnea, but only 10 million have symptoms and only 0.6 million have yet been diagnosed (leung, 2009).

Obstructive Sleep Apnea, is asleep disorder that involves cessation or significant decrease in the presence of breathing effort. The muscle tone of the body ordinarily relaxes during sleep and at level of the throat; the human air way is composed of collapsible walls of soft tissue which can obstruct breathing during sleep. Symptoms of OSA may include excessive sweating during sleep, nocturia, nightmares, dry mouth when awakening caused by sleeping with the mouth open. Cardiac manifestation like: Arrthmia, ischemic pain, myocardic infarction, development of high blood pressure, (dyspnea, wheezes, chronic irritant cough). Patients with sleep apnea may complain of neurological and psychological problems like (impaired mental function, slowed reaction times, problems in concentration, memory loss, personality changes such as irritability or depression, decreased interest in sex and nocturia (Chai-Coetzer et al, 2011).

Patient's needs: the department of health DH defines needs as the requirements of individuals to enable them to achieve maintain or restore an acceptable level of social independence or quality of life. Needsoriented theories emphasize the health professional's role in helping the patients to meet their physiological and psychosocial needs. Traditionally health authorities and other health-related organizations at local, regional and national level set out to provide appropriate services to meet population needs, seeking to achieve levels of heath 
improvement, an acceptable level of social independence and improved quality of life (Chung et al, 2008). Treatment for OSA depends on the medical history, severity of the problem and most importantly, the specific cause of the obstruction and there are no effective drug-based treatments for obstructive sleep apnea. Treatment involves lifestyle changes, behavioral changes, relaxation techniques and oral appliances, mandibular advancement device (MAD) and surgical intervention. But the best method to keep the airway open during sleep is Continuous positive airway pressure device (CPAP) (Brandon, 2011).

Nurses have a role in the diagnosis and management of the condition through appropriate questioning, observation, advice on lifestyle choices, and support for treatment. She can help OSA patients prevent lifethreatening physiology changes and improve the quality of their lives and the lives of those around them (University of Maryland Medical Center (UMMC), 2011). So, the first important nursing intervention occurs during the nurses initial contact with the patient, when the nurse identifies risk factors and assesses for symptoms. Nursing intervention begins with assessment, continues with referral, educational and psychological support, to prevent life-threatening physiologic changes and improve quality of the life (Park, 2011).

\section{Aim of the study}

Aim of this study is to assess the needs (Physical, psychological, social, spiritual and educational) of patients with obstructive sleep apnea (OSA).

\section{2- Subjects and Methods \\ Research design}

A descriptive exploratory design that was utilized to meet the aim of this study.

\section{Study setting}

The present study was conducted at sleep center in chest department at Assiut University Hospital.

\section{Study subjects:}

A purposive sample of all available patients (100) aged between (18-65 years) from sexes, female (54) and male (46) with OSA and who are willing to participate in the study.

\section{Tools of data collection}

Tool 1: Sleep Disorders questionnaire sheet, version 2.02) which was developed in a simple clear Arabic language by the researchers based on literature review and experts opinions in the light of relevant reference to identify the physical assessment and patients needs with OSA (Alan Douglass 1992). It included the main following parts: (Sociodemographic data, patient's medical record and patient's needs assessment sheet).

Tool 2: Patients' physical assessment sheet: It was used to assess and history taking for the following:
Head, ENT, chest, GIT, Cardiac, urinary system, sleep, special habits as smoking and alcohol.

Tool 3: Epworth Sleepiness Scale (ESS): This scale was developed by (John, 1991), translated into Arabic and modified by the researcher to measure daytime sleepiness. The scale covered 8 situations (watching T.V, reading, talking with others, time of rest, traveling, driving, after launch mail and setting down position). Patients rated from $0-3$, so the total score ranged from 0-24. Patients' grades were collected and recorded as follows: Normal (0 - 9), Mild (9 - > 12), Moderate (12 - > 18) and Sever (18 24).

Tool 4: Respiratory Disturbed Index (RDI): After full night examination on full Polysomnographic study (Smno-screen plus) was EEG, EMG, EOG and RERA. An index used to assess the severity of OSA based on the total number of complete cessations (apnea) and partial obstructions (hypopnea) of breathing occurring per hour of sleep. These pauses in breathing must last for 10 seconds and are associated with a decrease in oxygenation of the blood. In general, the RDI can be used to classify the severity of OSA. RDI $\leq 5$ events/hrs is considered normal, while RDI $5<15$ mild, $15-<30$ moderate and $\geq 30$ events/hrs is consistent OSA (Wileman et al, 2010).

\section{Tool 5: Hamilton Rating Scale}

It was developed by Hamilton (1990), translated into Arabic and modified by, to identify patient's level of depression. The scale cover 17 variables (HRSD-17), the total score ranged from 0-5. According to patient's response, the following classifications were adapted: The total score ranged from $0-23$.

\section{Face and content validity}

It was ascertained by a jury of 3 expertises from chest department and Medical-Surgical nursing department. Their opinions were elicited regarding the tool format layout, consistency and scoring system. The content of tools was tested regarding to knowledge accuracy, relevance, competence, understanding, applicability and, easiness from administrative minor modification were required.

Pilot study and Ethical considerations

A pilot study was applied on $10 \%$ of the studied patients with OSA, based on statistical percentage to test applicability and clarity of the tools, as well as to estimate the time needed to fill in the tools. Necessary modifications were done, and patients included in the pilot study were excluded from the study group. Prior to the pilot study, ethical approval was obtained from the Scientific Research Ethical Committee of Assiut University and written informed consent was obtained from each participant. In addition, they were assured that anonymity and confidentiality would be guaranteed and their right to 
withdraw from the study at any time without any reason.

\section{Filed work}

An official permission was obtained from the Faculty of medicine, Assiut University to the director of the study setting before starting any data collection, with explanation for the study aim to obtain permission and cooperation for data collection.

- Data were collected in Sleep center in Chest Department at Assiut University Hospital.

- Sampling was started and completed within one year, from February 2011 to June 2012.

- Purpose of the study was simply explained to patients who agree to participate in the study prior to any data collection.

- The researcher was available 3 days/ week, on morning and afternoon shifts to collect data from the studied patients.

- The following study tools were filled in and completed by the researcher once: Questionnaire sheet to assess the needs of studied patients, Epworth sleepiness scale to measure day time sleepiness, Stop Bang assessment sheet to screen patients for severity of OSA and Pulmonary function tests sheet. Filling in the tools was done according to the patients' understanding and health condition.

\section{Limitations of the study}

Events of 25 January 2011 which happened in all country affected on the sleep center work and affected on patients admitted in chest department at Assiut University Hospital. Moreover, completing the tools of data collection for patients take long time depending on their health condition.

\section{Statistical design}

The collected data were organized, tabulated and analyzed using the statistical package from social sciences (SPSS) version 17 from windows. Data were presented in tables and charts using numbers, percentages, means and standard deviations, added to Chi-square to determine significance for nonparametric variable. Level of significant was threshold at $0.05(\mathrm{P}>0.05=$ insignificant, $\mathrm{P}<0.05=$ significant and $\mathrm{P}<0.001=$ highly significant $)$.

\section{3- Results and data analysis}

This result shows that, characteristics of the studied sample, mean age of patients included in the study was $(42.55 \pm 11.75)$. Concerning gender, more than half of them $(54 \%)$ were female, and nearly half of them were illiterate and basic education $(30 \% \& 44 \%$ respectively).
Table (1): show relation between measurements among the studied patients as regard their gender. Results revealed that, more than $(77.8 \%)$ of studied female patients had abnormal waist size rather than male $(56.5 \%)$. More than one third of male (37.0) had abnormal neck circumference rather than female $(22.2 \%)$. As regard BMI, one third of male patients $(32.6 \%)$ had overweight rather than female had (29.6 respectively), but more than half of studied female patient $(51.9 \%)$ had obese; male less than half of them $(45.7 \%)$ had obese. Moreover, statistically significant differences between waist size as regards their sex $(p$-value $=0.023)$, no statistical significant difference between neck size and BMI with sex.

Figure (1): revealed percentage distribution of the studied patients according to their level of OSA according to their level of daytime sleepiness according to grades of ESS. Results show that, nearly $(45.0 \%)$ of the studied patients had moderate daytime sleepiness and $(38.0 \%)$ had severe daytime sleepiness.

Figure (2): showed percentage distribution of the studied patients according to their grades of depression according to Hamilton Depression Rating Scale. Results revealed that, more than four fifth of the studied patients $(20.0 \% \& 61.0 \%)$ had severe and very severe depression, and two cases only hadn't depression.

Figure (3): showed percentage distribution of the studied patients according to their level of OSA according to RDI. Results revealed that, $91 \%$ of the studied patients had severe OSA, 9\% of them had moderate OSA and not present any mild case.

Table (2): clarified relation between severity of OSA among the studied patients as regards their needs. Results showed that, highly statistically significant relation between level of OSA among the studied patients as regards their physical, social, educational $\&$ psychological needs. ( $\mathrm{P}=0.000$ respectively). While, no-significant relation was found between level of OSA and spiritual needs $(\mathrm{P}<0.063)$.

Table (3): clarified relation between levels OSA among the studied patients as regards co-morbidity. Results showed that, no statistically significant relation between level of OSA among the studied patients as regards their co-morbidity. Statistical significant relation was found between level of OSA and ENT problems $(\mathrm{P}<0.027 *)$.

Table (4): according to multiple regression analysis model, the odd developing social needs is significant higher among OSA patients with RDI $(>30),(\mathrm{OR}=$ $4.972), \&$ age $(>40),(\mathrm{OR}=2.23)$. 
Table (1): Relation between measurements among the studied patients as regard their gender $(n=100)$.

\begin{tabular}{|c|c|c|c|c|c|}
\hline \multirow{2}{*}{ Items } & \multicolumn{2}{|c|}{$\begin{array}{c}\text { Male } \\
(n=46)\end{array}$} & \multicolumn{2}{|c|}{$\begin{array}{l}\text { Female } \\
(n=54)\end{array}$} & \multirow{2}{*}{ P-value } \\
\hline & No. & $\%$ & No. & $\%$ & \\
\hline \multicolumn{5}{|l|}{ Waist size: } & \multirow{3}{*}{$0.023^{*}$} \\
\hline Normal: & 20 & 43.5 & 12 & 22.2 & \\
\hline Abnormal: & 26 & 56.5 & 42 & 77.8 & \\
\hline \multicolumn{5}{|l|}{ Neck circumference: } & \multirow{3}{*}{0.106} \\
\hline Normal: & 29 & 63.0 & 42 & 77.8 & \\
\hline Abnormal: & 17 & 37.0 & 12 & 22.2 & \\
\hline \multicolumn{5}{|l|}{ BMI: } & \multirow{4}{*}{0.821} \\
\hline Normal $(18.5-<25)$ & 10 & 21.7 & 10 & 18.5 & \\
\hline Overweight $(25-<30)$ & 15 & 32.6 & 16 & 29.6 & \\
\hline Obese $(\geq 30)$ & 21 & 45.7 & 28 & 51.9 & \\
\hline \multicolumn{6}{|c|}{$\begin{array}{ll}\text { Chi-square test } & \text { BMI = body mass index. } \\
* \text { Statistical significant difference }(\mathrm{P}<0.05) . & \end{array}$} \\
\hline Neck size: abnormal male ( $\geq 45 \mathrm{~cm})$ & \multirow{2}{*}{\multicolumn{4}{|c|}{ Abnormal female $(\geq 42 \mathrm{~cm})$}} & \\
\hline Waist size: abnormal male ( $\geq 102 \mathrm{~cm})$ & \multicolumn{2}{|c|}{ Abnormal female $(\geq 86 \mathrm{~cm})$} & & & \\
\hline
\end{tabular}

Figure (1): Level of daytime sleepiness according to Epworth sleepiness scale.

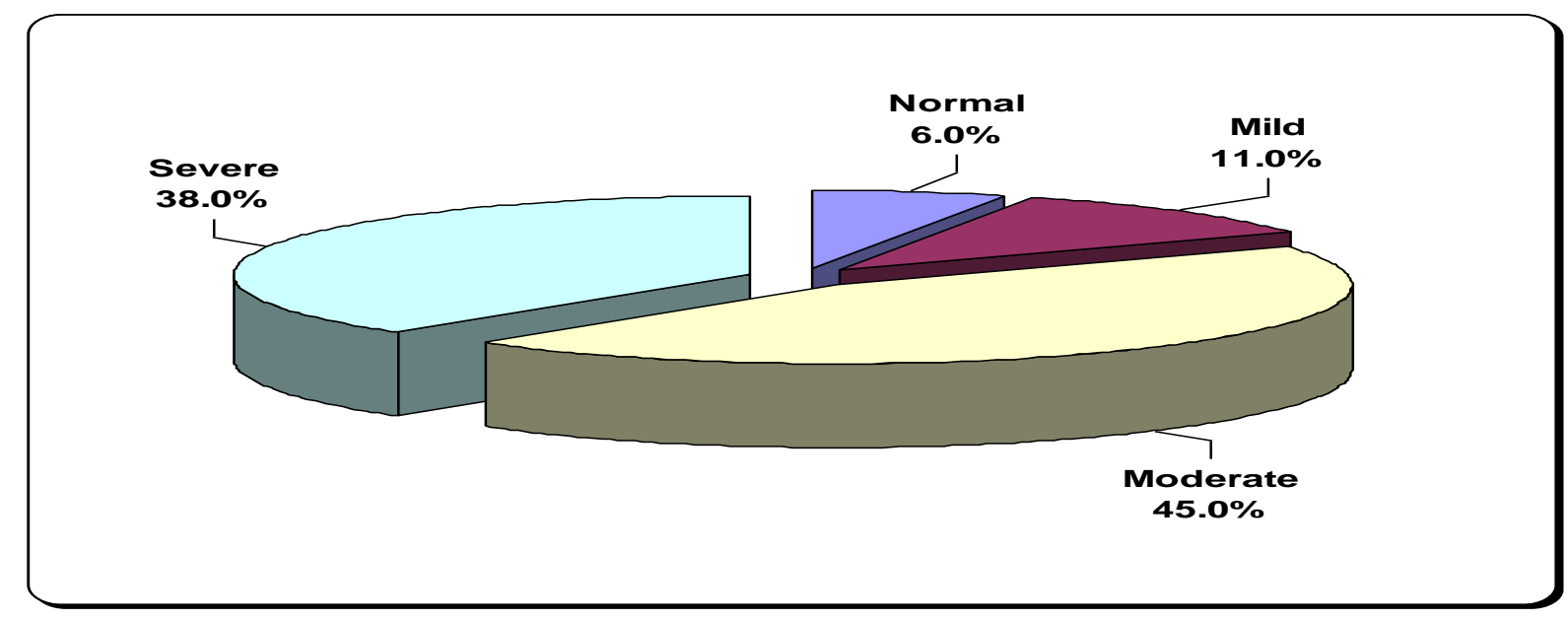

Figure (2): Level of depression according to Hamilton rating scale

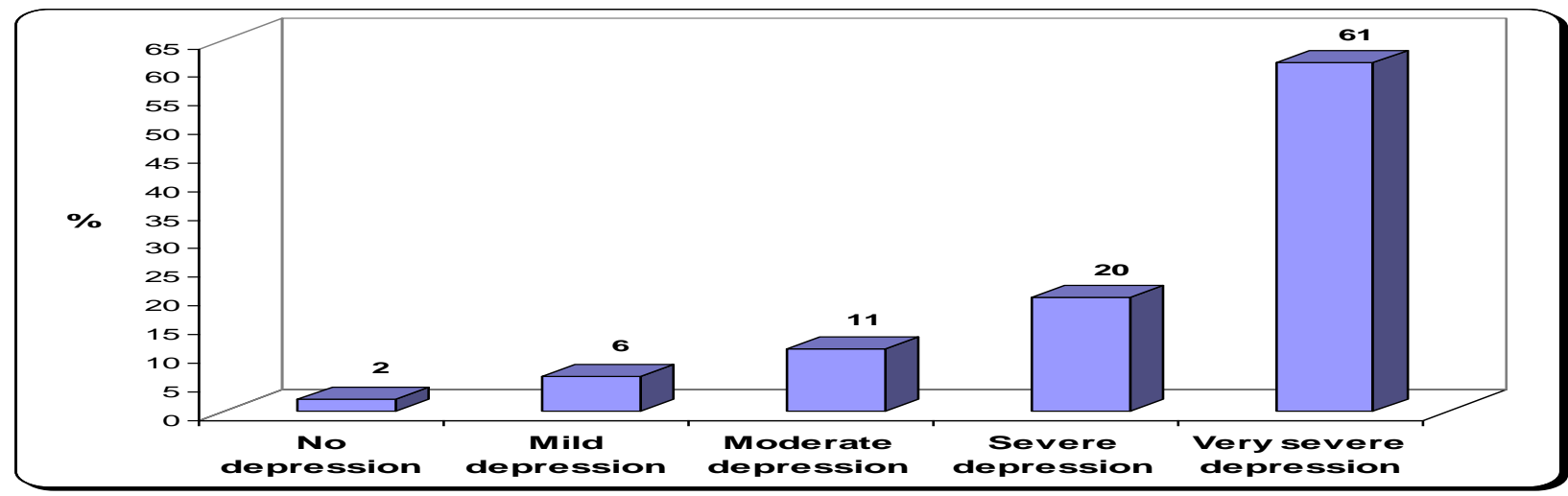


Figure (2): Level of Obstructive sleep apnea according to RDI

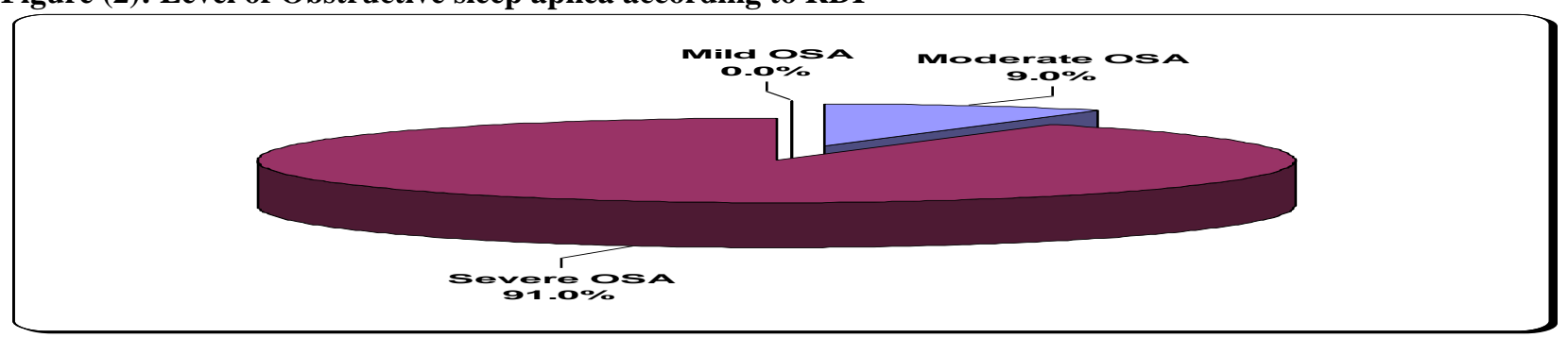

Table (3): Relation between severity of OSA among the studied patients as regards their needs $(n=100)$

\begin{tabular}{|c|c|c|c|c|c|c|}
\hline \multirow{3}{*}{ Needs } & \multirow{3}{*}{ Score } & \multicolumn{4}{|c|}{ Level of OSA } & \multirow{3}{*}{ P-value } \\
\hline & & \multicolumn{2}{|c|}{$\begin{array}{c}\text { Moderate } \\
(\mathbf{n}=9)\end{array}$} & \multicolumn{2}{|c|}{$\begin{array}{l}\text { Severe } \\
(\mathrm{n}=91)\end{array}$} & \\
\hline & & No. & $\%$ & No. & $\%$ & \\
\hline Physical & 10 & 5 & 55.6 & 91 & 100.0 & $0.000^{*}$ \\
\hline Social & 6 & 3 & 33.3 & 83 & 91.2 & $0.000^{*}$ \\
\hline Psychological & 5 & 3 & 33.3 & 78 & 85.7 & $0.001 *$ \\
\hline Spiritual & 4 & 2 & 22.2 & 55 & 60.4 & 0.063 \\
\hline Educational & 8 & 4 & 44.4 & 91 & 100.0 & $0.000 *$ \\
\hline \multicolumn{6}{|c|}{$\mathrm{P}>70.05=$ no significant } & $\mathrm{P}<0.0001=$ very highly significant $* * *$ \\
\hline
\end{tabular}

Table (3): Relation between levels of OSA among the studied patients as regards co-morbidity $(n=100)$

\begin{tabular}{|c|c|c|c|c|c|}
\hline \multirow{3}{*}{ Items } & \multicolumn{4}{|c|}{ Level of OSA } & \multirow{3}{*}{ P-value } \\
\hline & \multicolumn{2}{|c|}{$\begin{array}{c}\text { Moderate } \\
(\mathbf{n}=9)\end{array}$} & \multicolumn{2}{|c|}{$\begin{array}{l}\text { Severe } \\
(\mathrm{n}=91)\end{array}$} & \\
\hline & No. & $\%$ & No. & $\%$ & \\
\hline Respiratory system & 9 & 100.0 & 87 & 95.6 & 0.521 \\
\hline Digestive system (GERD) & 5 & 55.6 & 74 & 81.3 & 0.070 \\
\hline Cardiovascular systems & 1 & 11.1 & 9 & 9.9 & 0.907 \\
\hline Hypertension & 5 & 55.6 & 58 & 63.7 & 0.628 \\
\hline ENT & 2 & 22.2 & 55 & 60.4 & $0.027 *$ \\
\hline Urinary system & 6 & 66.7 & 62 & 68.1 & 0.928 \\
\hline Nocturia & 9 & 100.0 & 86 & 94.5 & 0.471 \\
\hline $\begin{array}{l}\mathrm{P}>0.05=\text { no significant } \\
\mathrm{P}<0.001==\text { highly significant } * *\end{array}$ & \multicolumn{5}{|c|}{$\begin{array}{l}\mathrm{P}<0.01^{*}=\text { significant } \\
\mathrm{P}<0.0001=\text { very highl }\end{array}$} \\
\hline
\end{tabular}

Table (4): Multiple regression analysis of the OSA for Social needs

\begin{tabular}{|l|c|c|c|c|}
\hline \multicolumn{1}{|c|}{ Variables } & \multirow{2}{*}{ P-value } & \multirow{2}{*}{ OR } & \multicolumn{2}{c|}{ 95.0\% C.I. } \\
\cline { 4 - 5 } & & & Lower & Upper \\
\hline Snoring & 0.147 & 3.801 & 0.626 & 23.090 \\
\hline Hypertension & 0.597 & 0.636 & 0.119 & 3.406 \\
\hline Digestive system (GERD) & 0.282 & 0.223 & 0.014 & 3.438 \\
\hline Sex (Male) & 0.942 & 1.063 & 0.209 & 5.391 \\
\hline Age (> 40 years) & $0.018^{*}$ & 2.229 & 1.522 & 2.836 \\
\hline Neck size (> 42) & 0.866 & 1.202 & 0.141 & 10.217 \\
\hline Waist size (> 86) & 0.862 & 0.853 & 0.141 & 5.150 \\
\hline Epworth (> 12) & 0.366 & 0.286 & 0.019 & 4.325 \\
\hline Hamilton (> 14) & 0.931 & 1.248 & 0.008 & 1.935 \\
\hline RDI (> 30) & $0.001^{*}$ & 4.972 & 5.381 & 9.694 \\
\hline C.I = confidence intervals. & \multicolumn{3}{|c|}{ OR = odd ratio } \\
\hline
\end{tabular}




\section{Discussion}

$\mathrm{T}$ his study is the first to assess patients needs with T Obstructive sleep apnea (OSA) in Egypt. OSA; it is fairly serious and often remains undiagnosed in primary care practice. The disorder is associated with significant morbidity and even some mortality, so family needs to be familiar with its clinical presentation and treatment (HRSD-17, 1990 and Park, 2011). The current study aimed to assess physical, social, psychological, spiritual and educational needs of patients with Obstructive Sleep Apnea. We evaluated these data from a multivariate perspective: characteristics of the studied patients, assessment of patients' needs: physical, psychological, social, spiritual \& educational, patient's levels of sleepiness, depression and OSA. In addition, relation between patients' characteristics, levels of sleepiness, depression and OSA as regards their needs.

In the present study, findings regarding patients' characteristics revealed that, mean age of the studied patients was $(42.55 \pm 11.75)$. This finding was supported by (AASM, 2010), said that, OSA occurs with the greatest frequency in people between the ages of 40-60 years.

As regards gender, in the current study females slightly exceeded males to develop OSA. This result was disagreement with (UMMC, 2011) recognized that OSA affects $3.5 \%$ of men and $1.5 \%$ of women. The incidence of OSA, among men is higher than in women with a ratio of $24: 9$ and this may be related to the anatomical issue in male as there is increased body mass in the torso and neck, especially through middle age and older. On the other hand, the

registration of Assiut Sleep center in Assiut University Hospital (2010 \& 2011), reported that the numbers of Egyptians safer from OSA in Assiut and in Egypt is unknown. The total number of patients with OSA and doing sleep study in sleep lab unit in Assiut University Hospital reported 148 cases, two thirds of them were female.

In relation to educational level, nearly half of patients were illiterate, read \& write, more than one fourth had secondary school. These results were supported by who mentioned that, patients with higher education had high global health status and the higher level of educational attainment, had lower OSA risk and hazards.

As regards body mass index, nearly half of the studied patients were obese, nearly one third of them had overweight and fifth of them had normal body weight. This result was supported by (Thomas et al, 2011) said that primary risk factor for OSA is excessive weight gain and the individual with OSA suffers from obesity, with particular heaviness at the face and neck.

Considering waist circumference, more than two thirds of the studied patients had abnormal waist. These findings were supported by the (WHO, 2010 \& Ahmed, 2011) who revealed that, waist-hip ratio is a risk factor especially in severe OSA, a normal waist line for a woman is $86 \mathrm{~cm}$ or less, and for a man is $102 \mathrm{~cm}$ or less

As regards the neck size the present study showed that, nearly one third of the studied patients were large neck and the percent of male more than female. This finding were supported by (ASAA, 2010), revealed that male hormones can cause structural changes in the upper airway.

On the light of the present study finding, as regards physical needs of OSA patients, majority of the studied patients needs to good sanitation to relive feeling of tiredness, shortness of breathing related to exposure to dust, needs assistance with physical activity \& prevent sleeping in supine position \& changing in sleeping hours. In addition more than half of them needs to eat particularly diet, eat an adequate amount of fluid, help others to carry out everyday activities \& relaxation exercises. Later, one fifth of them need to help during showering or wearing their clothes. These results were supported by (Marris et al, 2009) who said that multiple arousals with sleep fragmentation are the likely cause of excessive daytime sleepiness, un restful sleep, fatigue and muscles weakness in patients with OSA.

As regards social needs among the studied patients, majority of them need to good social relationship and improve their business. Followed by, need to reliving feeling of tired, improving of sleepy \& fatigued, increase of pleasure in daily life activities, reliving from irritable and motivated. These findings were supported by said that, when a person is diagnosed with OSA, he/she faced with many social problems, such as the breaking of everyday routine and the subjective perception of being a sick and less valuable member of the society. In the same context, nearly two third of them needs to enough income to can cover the cost of treatment, these results was supported by (Sands et al, 2010) who revealed that polysomnography is the good standard for confirming diagnosis of OSA and the test is expensive. Moreover, the multiple sleep latency tests may add to this cost and is not widely available.

Concerning psychological needs, the present study revealed that; reliving of stress, anxiety, fear \& insomnia represent the highest needs followed by reliving the feeling of not adapt to the changes related to their illness, improve good thinking in health state. These findings were supported by (ICSI, 2007) which said that family members and friends should 
give support and understand and accept the positive changes in your personality. Also, psychologists and psychiatrists play an important role in treating sleep apnea.

As regards to educational needs, all the studied patients needs to know the good health habits to sleep, amount of the seriousness of their health now. The majority of present study needs to reduce the incidence of their health now, risks, impact, signs \& symptom \& know meaning of OSA during sleep. This means that the patients were in need to more knowledge and correct practices to improve their self care. The previous result was supported by (Robert, 2012).

In relation to the level of daytime sleepiness, findings revealed that, less than half of the studied patients had moderate daytime sleepiness, more than one third of them had severe daytime sleepiness, and less than one fifth of them had mild sleepiness. It was observed that during this study some patients falls asleep during sedentary activities and embarrassing situations such as, when watching T.V, in a car, while stopped for a few minutes in traffic, sitting and talking to someone and when sitting and reading, the previous result was supported by (Robert, 2012).

Concerning the level of depression, as found nearly two thirds of the studied patients had very severe depression, while, about one fifth of them had severe depression \& less than one fifth had mild and moderate depression. This result was supported by (Montemurro et al, 2012) who said that, symptoms of OSA were associated with many depression symptoms including, feeling like a failure and feeling hopeless, sad feelings, decrease in self-confidence, inability to derive pleasure from things, and suicidal thoughts can attribute to OSA.

In relation to level of OSA among the studied patients as regards their needs Results showed that, highly statistically significant relation between level of OSA among the studied patients as regards their physical, social, educational \& psychological needs. While, no-significant relation was found between level of OSA and spiritual needs.

In relation to level of OSA among the studied patients as regards their co-morbidity, no statistically significant relation between level of OSA among the studied patients as regards their co-morbidity. Statistical significant relation was found between level of OSA and ENT problems. And according to multiple regression analysis model, the odd developing social needs is significant higher among OSA patients with RDI.

\section{Conclusion}

The findings of the present study indicated that, there was no statistically significant relation between patients' needs and their characteristics, levels of sleepiness, and depression. Statistical significant relation between level of OSA with patient needs and ENT problems, and between waist circumference and gender, educational needs with educational level.

\section{Recommendations}

The following recommendations were inferred from the study

- An orientation program should be prepared for patients with OSA, according to their needs.

- The nursing care should be given by the professional nurses and should be aware of OSA problems, how to prevent it and how to deal with it when develop.

- Work handbook for patients in a simplified manner powered Pictures guidance, the CPAP device, to demonstrate the use and benefits and its mode of operation and how to take care.

- Further research studies are needed to focus on the assessment of the quality of life for such group of patients.

- Ministry of health and Health Insurance Portability and Accountability (HIPAA) and health care organization must be covering the cost of investigation and treatment of OSA patients.

\section{References}

1- Cifci, T., (2011): Consequences of hypoxiareoxygenation phenomena in patients with obstructive sleep apnea syndrome. Annals of Saudi Medicine; 31 (1):1418.

2- Leung, R., (2009): Sleep-disordered breathing: autonomic mechanisms and arrhythmias. Progress in Cardiovascular Diseases; 51 (4): 324-38.

3- Chai-Coetzer, C., Antic, N., Rowland, L. Catcheside, P., Esterman A, Reed, RL. (2011): A simplified model of screening questionnaire and home monitoring for obstructive sleep apnoea in primary care. Thorax; 66(3): 213-9. Retrieved on: Mar/2011.

4- Goetting, C., \& Downey, R., (2010): Sick, symptomatic and undiagnosed. San Antonio, TX: 2010. Paper to be presented at the Annual Meeting of the Association of Professional Sleep Society.

5- Chung, F., Yegneswaran, B., \& Liao, P., (2008): STOP questionnaire: a tool to screen patients for obstructive sleep apnea. Anesthesiology; (108): 812-821. 
6- Brandon, P., (2011): Better Sleep Guidelines Top 10 Ways to Get a Better Night's Sleep Tonight. Retrieved on: 6/5/2010.

7- University of Maryland Medical Center (UMMC) (2011): Respiratory System and Anatomy of the Respiratory System. UMMC's Pulmonary Program ranked as one of the nation's 50 best by U.S. News \& World Report's 2010 "Best Hospitals" survey. Available at: www.SleepApneaMachine Answers.com.

8- Park, J., Ramar, K., \& Olson, E., (2011): Updates on definition, consequences, and management of obstructive sleep apnea, Mayo Clin Proc; 86 (6): 549-555.

9- Johns, M., \& Murra. L., (1991): A new method for measuring daytime sleepiness: the Epworth sleepiness scale. Sleep; 14 (6): 540-5.

10-Wileman, S., McCann, S., Grant, A., Krukowski, Z., Bruce, J., \& Samantha, M., (2010): Medical versus surgical management for gastro-esophageal reflux disease (GORD) in adults. Cochrane database of systematic reviews (Online) 3 (3): CD003243. Available at: www. PMID 20238321. com.

11- Alaa Eldin, T., (2011): Role of some recent trends in diagnosis and treatment of obstructive sleep apnea. Ph.D. Thesis, Chest Department, Faculty of medicine. Assiut University Hospital;198- 205.

12- Hamilton Rating Scale for Depression (HRSD17), (1990): To be administered by a health care professional) (presented as a service by GlaxoWellcome, February 1990) in UMass HealthNet: Consumer Health Resources for Massachusetts Residents: Official website of the Lamar Soutter Library, University of Massachusetts Medical School, Worcester, MA, 01655 USA. Retrieved on: 27/8/2008.

13- AAS M., (2010): The International Classification of Sleep Disorders, Revised. Westchester, Illinois: American Academy of Sleep Medicine.52-8.Available at: http://www.esst.org/adds/ICSD.

14- Thomas, B., Canapari, C., Hoppin, A., Kinane, T., Torriani, M., \& Katz, E., (2011): Relationship between Sleep Apnea, Fat Distribution, and Insulin Resistance in Obese Children. J Clin Sleep Med; 2011 Jun 15;7 (3): 268-73.

15- World Health Organization (WHO) (2010): Waist circumference and waist/hip ratio in relation to all-cause mortality, cancer and sleep apnea. European Journal of Clinical Nutrition; 64: $35-41$;

16- Ahmed, S., (2011): Effects of obesity and BMI on obstructive sleep apnea patients. Sleep in health and sick. Ph.D. Thesis, Chest Department, Faculty of medicine, Annals of Saudi Medicine.

17- Marris, M., Glozier, N., Ratnavadivel, R., \& Grunstein, R. (2009): Obstructive sleep apnea and depression. Sleep Med Rev;13 (6):437-44. Epub. Retroved on: 10/7/2009. http://www.sleep.health.am/sleep/more/sleephygiene/. Retrieved on: 19/09/2007.

18- Sands, S., Edwards, B. Kelly, V. Skuza, E., Davidson, M. \& Wilkinson, M.(2010):

Mechanism underlying accelerated arterial oxygen desaturation during recurrent apnea. Am J Respir Crit Care Med; 182 (7): 961-9. Retrieved on: 01/10/2010.

19- Institute for Clinical Systems Improvement (ICSI) (2007): Diagnosis and treatment of obstructive sleep apnea in adults. Bloomington (MN): Institute for Clinical Systems Improvement (ICSI); Retrieved on: Mar/2007.

20- Robert, P. (2012): Obstructive sleep apnea may be linked to depression. Available at: http://www.nlm.nih.gov/ Retrieved on: Friday 30/3/2012

21- Montemurro, L., Floras, J., Millar, P. Kasai, T., Gabriel, J., Spaak, J., (2012): Inverse Relationship of Subjective Daytime Sleepiness to Sympathetic Activity in Heart Failure Patients with Obstructive Sleep Apnea. Chest; Retrieved on: 26/4/2012. 